\title{
The Pursuit of Quality: Assessing Democracies... to Save Democracy?
}

\author{
Mauro Tebaldi, Marco Calaresu \\ Department of Political Sciences, Communication Sciences and Information Engineering, University of Sassari, \\ Sassari, Italy \\ Email: mcalaresu@uniss.it
}

Received 25 July 2015; accepted 23 October 2015; published 26 October 2015

Copyright $@ 2016$ by authors and Scientific Research Publishing Inc.

This work is licensed under the Creative Commons Attribution International License (CC BY).

http://creativecommons.org/licenses/by/4.0/

(c) †) Open Access

\begin{abstract}
For over a decade, there has been the widespread awareness that western democracies need to be reformed if they want to successfully cope with the crisis that they are experiencing; also, ultimately, if they want to be able to increase their own level of quality. The aim of this article is to illustrate why and how the quality of a democracy can (and indeed, must) be assessed with the purpose of improving it. Passing through a reflection on the state of the art of a major sector of studies in the international scientific scenario, and by presenting an original typological proposal to classify these same studies, we maintain that the crisis of democracy may be overcome, first of all, by improving the assessment skills of scholars and, secondly, by transforming the knowledge on democratic quality into useful knowledge for citizens.
\end{abstract}

\section{Keywords}

Quality of Democracy, Democracy, Crisis, Legitimacy, Efficiency

\section{The Crisis of Democracy...}

For over a decade, among political science scholars, in public opinion, and in many democratic governments and parliaments, there has been the widespread awareness that western democracies need to be reformed (Rondinelli \& Cheema, 2003) if they want to successfully cope with the crisis that they are experiencing in terms of legitimacy and efficiency (Dalton, 2004; Morlino, 2012; Papadopoulos, 2013; Gallagher, 2014); also, ultimately, if they want to be able to increase the satisfaction of their citizens and their own level of quality.

The political scientists of the 21st Century were not the first to be interested in the issues concerning the "crisis of democracy". Back in the first half of the 1970s, the interest of experts and scholars in democracies with proven stability — especially the mature West European and Anglo-Saxon liberal democracies—grew as regards 
the contradictions and possible crises in the development of democratic set-ups. Starting with the book by Michel Crozier, Samuel Huntington and Joji Watanuki (entitled, not by chance, The Crisis of Democracy) on the dangers of involution of the western democracies (Crozier, Huntington, \& Watanuki, 1975), followed soon afterwards by the work of Richard Rose and Guy Peters (with just as suggestive a title: Can Government Go Bankrupt?), there has been a steady increase in research on the problems weakening democracies to the point of undermining their foundations (Rose \& Peters, 1978). The "red thread" linking this type of study to others of the same kind seemed to be the realisation that the crisis of democratic regimes had particularly to do with two dimensions, closely interrelated, though analytically separable: legitimacy and efficiency.

\section{2. ... between Legitimacy and Efficiency}

The first dimension concerns the input side of the system, especially the support level, the breadth of which strictly depends on the degree of legitimacy of governments, institutions and political leaders. By legitimacy we mean, in line with the definition formulated by Leonardo Morlino, the set of positive attitudes society has towards its democratic institutions, considered the most suitable form of government by the members of the community (Morlino, 1998: pp. 25-33). Though the concept is elusive and subject to different interpretations, it draws the attention of researchers where there is the intention to trace back and analyse the sources of authority in democracy: those that assign the right to govern to leaders and the duty to obey attached to citizens.

When we speak of the "crisis of legitimacy" we are therefore hinting at a sensitive question that involves the adjacent concepts of consensus and support, and the importance of which is crucial in determining the state of health of democracies. Following the wave of participation of the Seventies and the associated dangers of decisional overload, nowadays these have, in fact, to cope with an almost generalised fall in rates of participation, both at political and administrative elections (Gray \& Caul, 2000) and in all the other forms of civic involvement (Pharr \& Putnam, 2000; Putnam, 2000), with the constant fall in levels of faith in the institutions (Newton \& Norris, 2000), especially governmental ones (Nye, 1997), and disaffection for politics of ever larger cohorts of citizens (Welzel \& Inglehart, 2005).

The second dimension of the crisis has to do with the output of the system, namely the political efficiency of democracies, which might be defined, following Gabriel Almond and Bingham Powell's insights, as the level of performance of government institutions in pursuing, providing and distributing political resources essential for the collectivity (Almond \& Powell, 1978).

When we speak of "crisis of efficiency" we are therefore referring to the dual challenge (Pasquino, 2005) faced by mature democratic regimes after the decades of stability following the end of the bipolar world and ideologies (with the fall of the Berlin wall) and the subsequent third wave of democratisation (Huntington, 1991): internally, the challenge comes from the growing demands of citizens, who press to obtain more and more extensive, substantial services and rights (Eckstein, 1971); externally, it comes down from the globalisation process, from integration between nations and the sustainability of the new democratisation processes (Nagle \& Mahr, 1999). The concept of efficiency, in this way, is expressed both in the actual capacity to generate safety and political order against internal and international threats, and by issuing a complex, diverse range of policies fit to tackle the remaining collective problems; moreover, by the capacity to activate suitable trends of macroeconomic regulation and redistribution to favour, in socio-compatible terms, the fair development of the global markets.

\section{Citizens' Expectations...}

If, on the one hand, the reasons for the democratic crisis come under the legitimacy and efficiency aspects, on the other, the crisis of democracies is also due to the high level of expectations citizens themselves have of the results democracies should achieve (Diamond \& Morlino, 2005: p. xxxiii).

Robert Dahl—in one of the most frequently quoted books on democracy (Dahl, 1989)—succeeded in being the first to grasp this side of the problem, emphasising how the conviction that democracy (in his words: "polyarchy") is not actually "democratic enough" and should be improved is typical precisely of those citizens living in countries where polyarchy has been in force for a long time. They sometimes declare that they have "had enough" of democratic institutions and despise their flaws, complaining of lack of faith in the political and governmental institutions, showing progressively greater distance from the political parties, and condemning the widespread corruption combined with a high degree of self-interest and irresponsibility of the policy-makers. On 
the contrary, the hope that one's own country may one day reach the threshold of democracy continues to be present in those democrats who live in nations still oppressed by non-liberal or not fully liberalised regimes. Dahl himself claims that it is not difficult to understand why those who are deprived of these institutions find them so desirable, even with their imperfections. It is more difficult to identify, however, which is the mechanism that manages to transform the hopes of those who have lived for some time with democratic institutions into democratic "malaise”.

\section{4. ... between Ideal Democracy and Real Democracy}

To understand what turns the aspirations of the citizens of mature democracies into democratic "malaise", we might start out from the assumption that nowadays in the West all, or almost all, alternative government systems to democracy seem to have failed or to have been somehow "absorbed" by the democratic paradigm itself. Of course, only a few of the theorists, but above all the citizens - the main consumers of the democracy asset-actually doubt if democracy can, in ideal terms, guarantee a range of rights and freedoms that no other system among its competitors is able to ensure. As Giovanni Sartori highlighted, however, there is always a certain distance between real democracy and ideal democracy, a gap that is extremely difficult (if not impossible) to fill (Sartori, 1987). One need only think that the American Declaration of Independence aimed at nothing less than the "pursuit of happiness" for all its associates, and that according to many classical and contemporary theorists, the greatest unresolved promise of democracy is exactly that of having failed in individual self-fulfilment.

It seems to be precisely this hiatus between citizens' expectations of what democracy ought to be and the "hard facts"- put differently, the hiatus existing between "ideal" democracy and "real” democracy-that engenders in citizens such a high level of dissatisfaction with their own regime. As Dahl recalled, the concrete institutional solutions experienced by citizens are actually nothing more than "imperfect approximations of an ideal”, where real democracies will never be able to respond perfectly to the very ideals that have generated them. And we believe it could not be otherwise. It could not, that is, be a simple task: due to the perfection of the many ideals that give life to the abstract models of democracy (freedom and equality above all) and the variegated imperfections with which individuals tangibly turn these ideals into systems of government and collective decisions. According to many scholars, the problem of quality, and of the assessment thereof, stems from this hiatus: to discuss the quality of a democracy, establish whether it is of a high or low level, basically means to make a comparison between its real aspects (what democracy is) and its ideal configuration (what democracy ought to be).

\section{Why Assess the Quality of Democracy?}

It is fair, at this point, to wonder how we can get out of the crisis of legitimacy and efficiency in democracy, at the same time raising the level of satisfaction of citizens and the overall quality of the regime: can quality be improved, for example, by constitutional reforms and constitutional adjustments, or might it be the composite outcome of many factors and elements which have to do not just with "constitutional engineering” issues but also with the expansion of the potential of citizens and society? Could a qualitative improvement in a democracy, if achieved, really manage to ease the growing alienation of citizens in many democratic countries and contribute to achieving greater legitimacy of the regime and greater satisfaction with its performance? Furthermore, suppose a government obtained a high score in many of the indicators selected to assess its quality, would it be able, at the same time, to guarantee an acceptable standard of national and international safety for its citizens, and if so, how? On the other hand, would a democracy that had not managed to achieve good quality results in several indicators, but managed to satisfy its own (informed and participating) citizens be considered a quality regime?

Scholars who focus on the assessment of democracy try to answer these key questions. The corpus of political science literature focusing on democratic quality aims in fact at isolating the conditions, which enable the reasonable functioning of democracy, e.g. the best among those practicable. To look at democracy with scientific method therefore means to cope with the evolutionary pathways-the theoretical ones and those actually experienced-that indicate "where", "how" and "what" to choose when planning the best possible application of ideal democratic models.

It is a perspective that unfurls a great heuristic potential, and may be an antidote to the crisis of democracy, both from the input and output sides of the system. Though remaining in the field of partial theories of politics (for we are speaking of democratic regimes, and them alone), it allows for the opening of a general theoretic 
umbrella of democracy, which analyses, within the polyhedric objective of quality, the entire range of processes, structures and results of democracy "as it is", to connect it up with "how we would like it to be" and "how it should be”, at all levels of government and according to the opinion of citizens.

\section{How to Assess the Quality of Democracy?}

Having stated why to assess the quality of democracy, we propose a two-dimensional typology which we consider it useful to understand how it is possible to assess it for scholars in this major sector of studies.

It concerns, first of all, the two perspectives from which we can study quality, represented by the categories of "politics" and "policy". For quality may be considered a characteristic associated, on the one hand, with the study of power, institutions, the dynamics of consensus and the circuit of political representation and, on the other, with the analysis of participation in decision-making arenas, and democratic governance in terms of policy and policy-making.

The second dimension of the taxonomy refers to the difference between two ways of understanding the subject of investigation, namely: democratic government. From an analytical point of view, this term can be broken down, into two different meanings: the "capacity to govern" and the "outcome of governing". The first explores the validity and structural strength of the democratic project: in this sense, democratic quality refers to levels of compliance, to the degree of conformity with models upon which the creation of institutions, arenas, organisations and procedures depend that are aimed at producing specific governing capacities. Whereas, the other meaning indicates that democratic quality depends basically on the results achieved: it is therefore a question of performance, understood as an assessment and comparison of the levels of democratic response to the demand expressed by the citizen, in terms of the relation between his expectations and the performance tangibly provided by institutions and decision-makers, according to a logic primarily aiming to assess efficiency and results achieved.

If we try to summarise democratic quality, this topic can be analysed, if observed in relation to "where", both as a "feature of politics" or as a "feature of policy". But when we wish to examine it from the viewpoint of "what" and "how", we may focus on both the ability to practice "capacity to govern" and the "outcome of governing” (Table 1).

If cross-referenced, the above dimensions lead us to identify and frame four possible types of approach to the study of democratic quality:

1) If we consider democratic quality as a "feature of politics", having as its subject quality as the "capacity to govern", we will pursue the "best government system" of democracies. According to the authors who have favoured this perspective of analysis, the key to democratic quality is form, the institutional scaffolding and representative structure that shape the government system. The consequences-a regime with good chances of working well, for example, in terms of responsiveness and accountability—stem from the constitutional design generated, assuming that the surroundings provide suitable conditions. The strength of the approach thus consists of its deductive rigour and not of the process of checking the effects foreseen. We may even say that in the works of authors who support this perspective, there is widespread awareness that the study of democratic quality basically concerns the potential of a regime, and its levels of compliance with certain standards, well before its actual results. According to those observing democratic quality from this perspective it is therefore a question of analysing and envisaging capacities and probable effects, but not results and outcomes of the said capacities.

2) If we consider democratic quality as the "capacity to govern”, but adopting a "policy" perspective, we may assess the "best decisional capacity" of democracies, rather than the "best government system".

Table 1. Types of approach to the study of democratic quality.

\begin{tabular}{lccc}
\hline & & \multicolumn{2}{c}{ Democratic quality is a... } \\
\cline { 3 - 4 } & & Feature of politics & Feature of policy \\
\hline Democratic quality is... & Capacity to govern & Best government system & Best decisional capacity \\
& Outcome of governing & Best systemic efficiency & Best decisional outcome \\
\hline
\end{tabular}


For if, on the one hand, democratic quality refers to the mechanisms and results of "vertical democracy", based on the fundamental relationship between representatives and the represented, on the other hand, it leads to considering the effects of "horizontal democracy": where the influence of other logics of action become clear, since those who participate and decide in certain policy sectors are often completely remote from the awards and sanctions distributed in the electoral-representative circuit. Focusing on the arenas and policy-making processes, the objective of these studies is therefore to provide empirical evidence concerning the problem of which are the best forms of democratic governance. Authors ascribable to this research trend do not hesitate to suggest what conditions and organisational routes can lead, better than others, to designing governance able to offer good decisional efficiency and high levels of legitimacy, at the same time minimising the risks of probable and potential causes of democratic failure (exclusion of disorganised citizens, strengthening of social inequalities, weakening of public authorities, accentuation of distributive collusions, etc.).

3) If the subject of the research becomes the "outcome of governing", considering quality from the "politics" point of view, the focus will be on the "best systemic efficiency" of democracies.

This approach is based on the quality of the results and shifts the argument onto the systemic outputs of democracy. What count is the check on how much the decisions are effectively conditioned by citizens and respond to their will: the outcome of governing. According to those who adopt this research perspective, democratic quality is the result of a logic based mostly on the results achieved: more precisely, it is a question of performance, of how and how much to be able to raise the efficiency of systems and decisional structures, to the point of reaching certain performance levels, or at least obtaining a certain degree of satisfaction on the part of the citizens. Whatever the methodological course chosen (analysis of performance using benchmarking techniques, or analysis of citizen satisfaction by customer satisfaction techniques), what the researcher perceives when he embarks on the path of measuring decisional outcomes to assess democratic quality, is the need to establish a logical connection between "good governing" and "good democracy". This connection can be found by examining the results of government action and its impact on society. As well as sharing this basic hypothesis, authors who pick decisional performance as the fundamental subject of the study of democratic quality tend to adopt methods of analysis of an inductive type, with the use of multiple comparative strategies. The objective is to establish, taking a reverse route-from the detailed to the general-which phenomena can explain the variance of the dependent variable (democratic quality in terms of performance), in that they are significantly correlated with it.

4) If the subject of assessment remains the "outcome of governing", with the adoption of a "policy" perspective, the efforts to assess the democratic regime prove to be aimed at singling out the "best decisional outcome" of democracies, rather than the "best systemic efficiency".

In the field of public policy analysis, assessment plays a particularly crucial role, since it identifies the processes and instruments thanks to which the performance of government work is measured. For those observing democratic policy from the "best decisional outcome" angle, the purpose is to understand how and to what extent policy outcomes contribute to the solution of a collective problem. In this sense, the core of evaluation research is, in itself, a question that has to do with the quality of the decisional performance of democracy (namely, with an opinion on government work): it becomes extrinsic in the validation or falsification of an impact hypothesis of an independent variable (a certain public policy) on a dependent variable (the behaviour of those the policy is aimed at) within a model of causal relations. According to the scholars that adopt this research approach, the government action in democratic countries can gain advantages, in qualitative terms, from an assessment system that works well and has as its subject the performance of the government itself. Such a system, when effective and efficient, would allow to identify the impact of decisions (or that of decisions to be made, to be anticipated), be it on the side of demand (the citizen-principal), or on that of supply (the representativeagent).

\section{Conclusions}

Our typological proposal on the possible approaches to democratic quality operates under the awareness that in the literature on the subject of quality analysis, classifications exist that are drifting considerably aside, since they are based on theoretical prerequisites that on each occasion aim to focus on (and consequently distinguish) criticalities, dimensional links, operationalisation issues and empirical research that are entirely different.

Taking a closer look, the current scenario of research which is ascribable to the theme of democratic quality does not follow a single direction, though some efforts are being defined to create a dominant paradigm. This 
seems, at the moment, to be its main criticality. On the one hand, we can configure this scientific undertaking as an enormous "open building site" for democratic development. On the other hand, this metaphor needs to be defined better: it is a building site where heterogeneous structures are designed and built, with different techniques and by skilled workers, each one committed to honing his tools and using construction materials that are basically inconsistent with each other. The result is that in the ideal balance we are starting to draw up, fragmentation places at least two penalising factors on research on democratic quality, two negative elements that are worth noting: first, the difficulty of proceeding to systematically accumulates the huge quantity of studies and empirical findings that are being produced in each sub-sector; secondly, the tendency to give many one-sided interpretations of the problem appears to grasp important facets of quality in democracies with just as much clarity that, observed from other perspectives, appear to grasp important facets of quality in democracies with just as much clarity.

For these reasons, as we pass from this brief evaluation to identify the challenges that will rest with researchers in this field of studies in the near future, we can single out four pillars which are crucial to increase the quality of the analysis of democratic quality and democracy itself.

\subsection{Implementing Plans for Complex Research, But Holding onto Parsimony of Theory}

This is an ambitious objective, but feasible, as long as the theory embarks on a pathway that is able to keep together the different levels of analysis of the phenomenon. The first level refers to the dual level of politics and of policy on which democratic quality may be measured, and to the factors that, on the respective planes, appear to take on an unusual illustrative force. Onto this first level, the territorial one is embedded, since political structures, processes and outcomes (be they observed from a politics or a policy perspective) convey traits and characteristics that are qualitatively different depending on whether they are analysed in contexts of local, national or supranational democracy.

Since the quality of democracy is the result of the overlapping of these multiple levels of analysis, the challenge consists of developing a theoretical picture able, with a limited number of independent variables, to explain how the product and government organisation can favour, in according to the opinion of citizens, the individual and collective well-being of communities equipped with regulations and democratic procedures.

\subsection{Exploring the Effect of Antinomies between Some of the Political Assets of Democracy within the Dimensions of Democratic Quality}

Whichever way we look at it, empirical assessment of democratic quality is based on implicit reasoning, according to which the highest degree of quality is given by contextual maximisation of the values obtainable, for the greatest number of dimensions that characterise the phenomenon.

If we attempt to critically observe this method of analysis and focus our argument on the prevalent models (those that aim at examining democratic politics), a major interpretative problem seems nevertheless to arise from the theoretical and methodological viewpoint, should we wish to take into consideration the tensions existing between certain public policies, namely between the production of certain political assets, and some of the principal dimensions of democratic quality, in particular substantive ones (identified as equality and freedom), procedural ones and those pertaining to content (rule of law, accountability and responsiveness). The size of this impasse for the conceptualisation of democratic quality is well argued by Ronald Pennock, who acknowledges the tensions existing between these political assets: safety and freedom, well-being and justice may clash; more of one may entail less of another (Pennock, 1966: pp. 415-434). Moreover, the level of development and capacity of a political system, its ability to produce these assets, and environmental threats and problems may limit the type and volume of political assets that it is possible to produce, at a given moment, in a given context.

Following Pennock's reasoning, it can be inferred that democratic quality is not always achieved by expanding, contextually and to its maximum, the dimensions identified. We believe this should be kept in mind when, after an assessment of democracy, there is the will to go on with a reform. Particular types of political assets, including safety, a crucial element of a peaceful, organised civil community, could succeed in determining the characteristics of politics and the structure itself of democratic quality. Up to what point, for example, can democracies accept the temporary or permanent suppression of some forms of freedom, so as to raise their level of internal safety? Could we say, in these cases, that the safety policy determines the politics of democratic quality? Can we assume that the need for rule of law, responsiveness and accountability tends, when there is a primary 
need like safety at stake, to put the other dimensions of democratic quality in second place, freedom and equality in particular?

If these hypotheses are supported by enough empirical evidence, it is plausible to reformulate the quality democracy model, asserting not only that the dimensions used to empirically establish the level of quality within a polyarchy do not necessarily tend to co-vary synchronically but, above all, that quality is not the product of synchronic co-variation upwards. To obtain greater democratic quality it is possible to raise some parameters, lowering others. In other words, in certain conditions (e.g. the arenas where territorial integrity is threatened, or those where terrorist threats and action develop) high levels of democratic quality can be obtained, in relation to the specific demand of citizens concerning individual and collective safety, even "bearing" as regards other factors of democraticity, such as personal freedoms, usually considered intangible when the need for safety is under the full control of the government.

\subsection{Adjusting the Comparison}

If we wish, then, to deal with the more strictly methodological approaches that aim to observe the quality of democratic regimes, we will concentrate on pointing out three issues inherent in applying the comparative method to a field of analysis like this one.

The first question concerns the degrees of generality on which the research is conducted, and corresponds first of all to choosing at what point of the ladder of abstraction, it is advisable to stop when we intend to define the subject of analysis. The question could be asked as follows: which notions of democracy enable empirical reference-points to be identified that is appropriate for a survey on the quality of a regime, and which do not? The point is not a foregone conclusion, for it is well known that the supporters of exacting definitions (in our opinion, preferable) who tend to reduce the size of the units under analysis, are opposed by those who defend the use of less descriptive definitions, the adoption of which allows the entry of a larger number of potential cases into the category of units that can be subjected to research on quality, including those regimes considered imperfect or defective democracies by the majority.

Another critical passage in conducting good comparative surveys is the selection of cases, and it is a point that shows itself to be particularly sensitive also in empirical analysis of democratic quality. As we have seen, quality democracy is studied using multi-dimensional models which look at a complex series of properties that can be attributed in variable degrees and proportions to the functioning of democratic systems. Given that the empirical universe of comparable cases consists of all the units that satisfy the definition of the democracy adopted, one of the problems to be faced concerns the sampling procedure, e.g. the selection of a certain sub-group that will be the actual subject of the research. The point here is the balance between extensive strategies (many cases, few variables) and intensive ones (few cases, many variables). If we go too far in the extensive direction, the risk is losing sight of the specificities of the different cases, with regard to fulfilling the dimensions of democratic quality. Going too far in the opposite direction may, on the one hand, enable this problem to be avoided but prevent, on the other, wide generalisations being made. The most promising route, from the point of view of desired balance, consists of concentrating the analysis on a limited but significant number of core cases properly classified by type and diversity. Delimiting the empirical universe like this also enables the researcher to make use of a variegated stock of techniques, both qualitative and quantitative, as regards the dual theoretical tension that inevitably pervades such complex research plans, positioned constitutively between generalising requirements and individualising counter-thrusts.

Finally, there is a third impasse that accompanies the comparison from a diachronic point of view. Since democratic quality, especially at the level of regime analysis (politics), is the result of dynamics whose roots run deep in historic events, even remote ones, it is worth asking ourselves how to determine temporal series able to grasp the "quality cycle". That is to say, which breaks, for the cases under examination, appear to outline important discontinuity, a before and an after, in the qualitative development of the democratic regime.

\subsection{The Pursuit of Quality: Transforming Knowledge on Democratic Quality into Useful Knowledge for Citizens}

The last point deals with a highly significant problem, when the political science debate on democratic quality is taken back to the prescriptive objectives that define it. David Easton clearly expresses the general assumptions of this argument. He claims: "Like all social knowledge, political science has its origins and continuing support in the obvious fact that human beings find it useful. If men did not feel that political science does or might ulti- 
mately satisfy some human purposes, it could scarcely have existed for over two thousand years... The utility of political research stems from the fact that it helps men to decide upon the kind of political system they would prefer and to understand how to go about changing social policy to obtain it”, (Easton, 1953: p. 223).

Retracing this opinion back to the objectives set down in the papers on democratic quality, we can add an important warning. Political science knowledge on democratic quality may turn into useful knowledge for citizens if it manages to overcome a problem, which Angelo Panebianco considers "largely unresolved in the liberal democracies". Using the Italian political scientist's words, this problem consists of defining "the space that it is reasonable to assign to technical knowledge (be it the administrator's knowledge or that of the consultant-expert) in the decision-making processes, without crossing the borders beyond which liberal democracy turns into a masked form of authoritarian regime”, (Panebianco, 1989: pp. 563-596).

In other words, it is a matter of avoiding a bizarre outcome: that knowledge about democratic quality may generate less democratic quality instead of increasing it. This could happen if, for example, information on the degree of functioning of the regime, instead of nurturing the virtuous processes of responsiveness and accountability, were to remain locked up in the cramped technocratic structures of the "guardian government" or succumb to the irresponsible interpretation of ideological criticism.

The transformation of knowledge into power is an attractive strategic instrument for those seeking to keep sound their own capacities for managing power itself, or for those who, on the contrary, are trying to challenge them. The point is that knowledge on democratic quality may positively influence good democracy the more it spreads among citizens in a basically free and equal way, but certainly not when it comes under the service of this or that oligarchy. Only in this way can knowledge that is nurtured on the opinion of citizens give them back their longed-for supremacy.

\section{Competing Interests}

The authors declare that they have no competing interest.

\section{Authors' Contributions}

This article is the result of joint research undertaken by the two authors. Mauro Tebaldi wrote Para. 5, 6 and 7; Marco Calaresu wrote Para. 1, 2, 3 and 4. Both authors read and approved the final manuscript.

\section{Acknowledgements}

The authors wish to thank the anonymous referees for their thorough review and highly appreciate the comments and suggestions. A special thanks to Christine Tilley and Tonito Solinas at University of Sassari, for their continued support in proofreading and editing this work.

\section{Funding}

The research has been funded by a PRIN National Grant 2010-2011 (Ministry of Education, University and Research) entitled "Crisi economiche e qualità delle democrazie in Europa-Economic Crisis and the quality of democracies in Europe". Scientific National Coordinator: Leonardo Morlino. Leading Institution: Libera Università Internazionale degli Studi Sociali Guido Carli (LUISS), Rome, Italy. Scientific Local Coordinator: Mauro Tebaldi. Local Institution: University of Sassari, Department of Political Sciences, Communication Sciences and Information Engineering, Sassari, Italy. Duration: 36 months. Protocol number: 2010WKTTJP_007. Area: 14

\section{References}

Almond, G. A., \& Powell, G. B. (1978). Comparative Politics. System, Process and Policy. Boston: Little, Brown and Co. Crozier, M. J., Huntington, S. P., \& Watanuki, J. (1975). The Crisis of Democracy. New York: New York University Press. Dahl, R. A. (1989). Democracy and Its Critics. New Haven, London: Yale University Press.

Dalton, R. J. (2004). Democratic Challenges, Democratic Choices: The Erosion of Political Support in Advanced Industrial Democracies. Oxford: Oxford University Press. http://dx.doi.org/10.1093/acprof:oso/9780199268436.001.0001

Diamond, L. J., \& Morlino, L. (2005). Assessing the Quality of Democracy. Baltimore: Johns Hopkins University Press. 
Easton, D. (1953). The Political System: An Inquiry into the State of Political Science. New York: Knopf.

Eckstein, H. (1971). The Evaluation of Political Performance. London: Sage.

Gallagher, T. (2014). Europe's Path to Crisis: Disintegration via Monetary Union. Manchester: Manchester University Press.

Gray, M., \& Caul, M. (2000). Declining Voter Turnout in Advanced Industrial Democracies, 1950 to 1997. The Effects of Declining Group Mobilization. Comparative Political Studies, 33, 1091-1021. http://dx.doi.org/10.1177/0010414000033009001

Huntington, S. P. (1991). The Third Wave. Democratization in the Late Twentieth Century. Norman: Oklahoma University Press.

Morlino, L. (1998). Democracy between Consolidation and Crisis. Parties, Groups, and Citizens in Southern Europe. Oxford: Oxford University Press. http://dx.doi.org/10.1093/0198280823.001.0001

Morlino, L. (2012). Changes for Democracy: Actors, Structures, Processes. Oxford: Oxford University Press.

Nagle, J. D., \& Mahr, A. (1999). Democracy and Democratization: Post Communist Europe in Comparative Perspective. London: Sage.

Newton, K., \& Norris, P. (2000). Confidence in Public Institutions: Faith, Culture, or Performance? In S. J. Pharr, \& R. D. Putnam (Eds.), Disaffected Democracies: What's Troubling the Trilateral Democracies? (pp. 52-73). Princeton, NJ: Princeton University Press.

Nye, J. (1997). Introduction: The Decline of Confidence in Government. In J. S. Nye, P. D. Zelikow, \& D. C. King (Eds.), Why People Don't Trust Government? (pp. 1-19). Cambridge, MA: Harvard University Press.

Panebianco, A. (1989). Le scienze sociali e i limiti dell'illuminismo applicato. In A. Panebianco (Ed.), L'analisi della politica (pp. 563-596). Bologna: Il Mulino.

Papadopoulos, Y. (2013). Democracy in Crisis? Politics, Governance and Policy. Basingstoke: Palgrave MacMillan.

Pasquino, G. (2005). The Quality of Democracy. Working Paper Series, Paper No. 002-1/4, Oxford: Centre for the Study of Democratic Government, Department of Politics and International Relations, University of Oxford.

Pennock, R. J. (1966). Political Development, Political Systems, and Political Goods. World Politics, 18, 415-434. http://dx.doi.org/10.2307/2009763

Pharr, S. J., \& Putnam, R. D. (Eds.) (2000). Disaffected Democracies: What's Troubling The Trilateral Countries? Princeton, NJ: Princeton University Press.

Putnam, R. (2000). Bowling Alone. The Collapse and Revival of American Community. New York: Simon \& Schuster.

Rondinelli, D. A., \& Cheema, S. (Eds.) (2003). Reinventing Government for the Twenty-First Century: State Capacity in a Globalizing Society. Bloomfield, CT: Kumarian Press.

Rose, R., \& Peters, B. G. (1978). Can Government Go Bankrupt? New York: Basic Books.

Sartori, G. (1987). Theory of Democracy Revisited. Chatham, NJ: Chatham House.

Welzel, C., \& Inglehart, R. (2005). Liberalism, Postmaterialism, and the Growth of Freedom. International Review of Sociology, 15, 81-108. http://dx.doi.org/10.1080/03906700500038579 